Vol. 8, Issue 10, October 2021

DOI: $10.17148 /$ IARJSET.2021.81026

\title{
Modern day Homa farming for fighting pandamic
}

\author{
Haraneswaran $T^{1}$, Sandiya $\mathbf{R}^{2}$ \\ ${ }^{1} \mathrm{UG}$ - BFSC Tamil Nadu Agriculture Umiversity \\ ${ }^{2}$ MSC Seed tech - Tamil Nadu Agriculture Umiversity
}

\begin{abstract}
The Recent Pandamic Covid19 has invited the necessity of healthy food, which in turn was helpful in fighting the pandemic ,through Homa farming which was followed at the time of vedhas were re started \& some new innovations like amino acid introduction \&alkaloids introduction have helped to improve the soil quality \& quality of the produce which is highly helpful in fighting the pandemic. Apart from this the produces were helpful in after covid psychiatric issues like addiction to the video games,alchohol consumption by adults \& adolescents.
\end{abstract}

\section{INTRODUCTION}

HOMA Therapy comes from VEDAS, the most ancient body of knowledge to man.

HOMA Therapy is totally a revealed science. It is as old as creation. In the course of time this knowledge was lost but it is now being resuscitated to give people guidance about how to correct polluted conditions of the planet we find ourselves in today. When things go wrong due to pollution, the elements of nature begin to change. The cohesion of atoms, fusion of atoms, begin in a different way as it is described in ATHARVA VEDA. It is stated if atoms begin refusion and fission in an improper way, a civilization could be destroyed. If HOMA is performed when this takes place it helps mould things harmoniously and a new, beneficial element is produced. Notice we do not say created. Nothing is created, only reshaped. This knowledge is HOMA Therapy.

THIS KNOWLEDGE CAN BE USED BENEFICIALLY TO GROW CROPS WITHOUT CHEMICALS AND PESTICIDES. THIS IS HOMA THERAPY ORGANIC FARMING. The process of AGNIHOTRA PYRAMID FIRE is the basic HOMA. AGNIHOTRA is a must to sustain life now.

\section{EXPERIMENTAL METHODS OR METHODOLOGY}

HOMA Therapy is given at a time when all hope is gone. It is given for all people. Anyone can do it, incorporate it in his or her daily life. HOMA has such a profound effect on plant life. It has a beneficial effect on animals including mankind but would be more easily detected in plants as they are a more simple organism.

SCIENTISTS CARRY THE FATE OF THE WORLD. We can teach you how to grow crops, how to get maximum yield out of minimum agricultural area, how to keep soil fertile, how to keep water pure, how to keep atmosphere nutritious. All this forms part of HOMA Therapy.

How the seed is treated, when the seed is to be planted, how to nourish the crops, how to harvest, when it is all contained in the Vedas, a treasure house of knowledge awaiting scientist. All we have to do is to tap into the source.

We think we have found the technological paradise. It will be our hell in the next years. Whether we like it or not we have already handed ourselves on a silver platter of technology into the jaws of death.

Science and technology are different things. Science is the search for truth. What technology has done and persists in doing is nothing short of raping the land and the air that we breathe of all nutrients by destroying plant life with pesticides and insecticides and polluting human beings with chemical fertilizers and food additives. All this is taking toll now. Man cannot survive this era without a massive attempt to counteract the destruction.

We have nearly reached a stage where there will be no reliable uncontaminated natural resources. All of our water supply will be polluted. In some areas there will be severe droughts and in others terrific floods. We should understand that these times have already begun. WE MUST RELY UPON SCIENTIFIC MEANS TO UNDO THE EFFECTS OF POLLUTED CONDITIONS IN ATMOSPHERE, SOIL, WATER AND ALL LIFE FORMS. The scientists and governments know this. However, man's awareness is blanketed by myths of prosperity and by his ignorance of environment. The age of complacency is coming to a violent end and hence the need for HOMA Therapy. We request the scientist to investigate the effectiveness of HOMA Therapy in undoing the effects of pollution.

All living things in nature, plants, trees, forests, the crops we plant, animals and human beings are exposed to such terrific pollutants that it becomes difficult to escape the deleterious effects. Micro organisms are rapidly dying in the soil. There will be no food to eat unless there is HOMA atmosphere. AGNIHOTRA, the basic HOMA, is the way to save the world now. If anyone can show a better, easier, more practical way, we are willing to listen. 


\title{
International Advanced Research Journal in Science, Engineering and Technology
}

\author{
Vol. 8, Issue 10, October 2021
}

\section{DOI: 10.17148/IARJSET.2021.81026}

When seepage begins from nuclear reactors and nuclear waste disposal systems, people in those areas will feel as if they are living on a keg of dynamite. People will become angry with scientist for what they have done, for their lack of thoroughness when they began experimenting with radioactive materials, for not looking to the ramifications of misusing such power or for creating such a powerful menace. The scientists will be hard pressed for solutions. They will work diligently, relentlessly for answers. The answer is here. The answer is AGNIHOTRA HOMA and the revealed knowledge the powers that be have chosen to give through us. Do not believe in what we tell you. Try AGNIHOTRA and be convinced on your own. We ask the scientist to investigate.

With chemical fertilizers and pesticides it becomes necessary to increase the dosage and strength or alter formulas as years go by. Then a stage comes when nothing grows unless you use them. If you do use them they ruin the soil and subsoil water. The harmful chemicals are ingested into the body when we eat food grown under these conditions. Then a few years later nothing grows at all and land that was once fertile and produced abundant crops has to be abandoned. These are some of the reasons why several communities started thinking in terms of organic farming and biological pest control. This worked for a while but as pollution content of the atmosphere increased and things got compounded, organic farmers came into terrific difficulties.

With increased doses of acid rain the top few inches of the soil on earth are likely to be totally destroyed so that nothing will grow. The answer to our ills lies just few inches beneath the surface of the Earth. Homa Therapy farming is the way out.

Elements begin to change due to pollution. Somehow due to magnetic pull setup where HOMA is performed the elements required to make certain life sustaining essentials are again attracted to the planet by some other mode of transference. Some may even come from other planets.

Changes in soil composition due to pollution become drastic and the results become disastrous. Soil becomes unable to sustain plants and even life. The way out is to inject nutrients and fragrance into the atmosphere by widespread practice of HOMA.

Soil in many places becomes unable to support plants due to pollution. Then trees die for unknown reasons. Yet when Agnihotra is performed plants dance and thrive. They are thankful for the nourishment HOMA gives.

The molecular change in the fission and fusion of atoms causes properties of elements to change in atomic structure and weight. Electrons and neutrons rotate at varying speeds. If proper insight is given to scientists we can show them how this knowledge can be used beneficially in some areas when looked at from HOMA perspective.

The composition of nutrients in the soil deteriorates and this has a great impact on the food supplies. Pollution is the disease. HOMA is the cure. The practice of HOMA replenishes the nutrients that are robbed from our environment by pollution. The chemical and molecular structure of bacteria change and they become more immune to conventional medical methods. If we practice HOMA things will improve.

\section{RESULTS AND DISCUSSION}

\section{CROP YIELD}

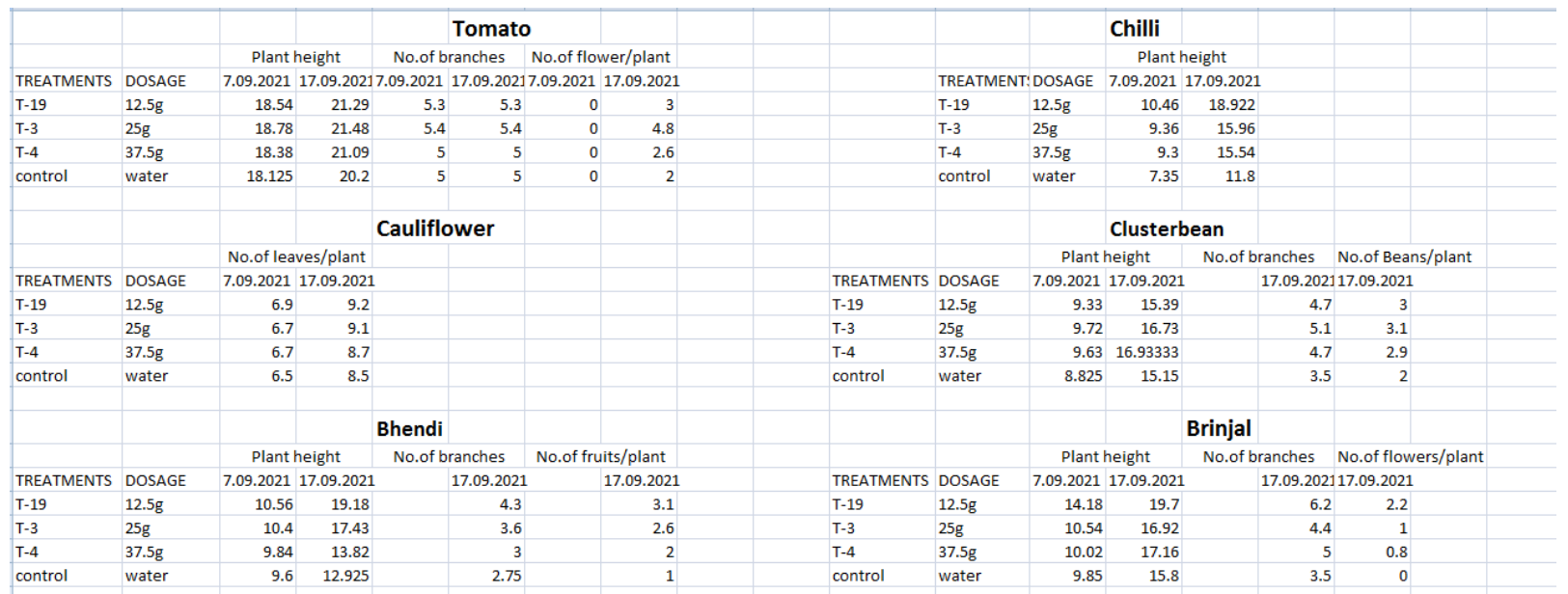

When growing plants in Agnihotra atmosphere do not necessarily expect the plants to become large; instead observe the size, quality and appearance of the vegetable, fruit or flower. All the energy of the plant goes towards yield because by performance of HOMA we make the plants happy.Energy patterns of plants are arranged in such a way that when HOMA is performed the injection of nutritional content into the atmosphere helps shape and mold these patterns harmoniously so that the result is fantastic yield and excellent quality. Agnihotra is the basic HOMA.A strange 


\section{DOI: 10.17148/IARJSET.2021.81026}

phenomenon occurs when plants are bred in Agnihotra atmosphere. An aura type field of energy is generated from the plant and exists around the plant while Agnihotra is performed in its proximity. The field contains nutrients and vibrations of Love. The plant is continually able to draw on this resource that is given by performance of Agnihotra in the area. This gives the plant the ability to maintain maximum growth and yield levels. At the same time a feedback of Love is given to the area, helping to negate the effects of thought pollution.

Fruit trees will yield fruit double the usual size and with twice the meat if Agnihotra and HOMA are performed regularly in the orchards. Orange would be a good fruit to begin with as it will quickly, almost immediately, give results. Tangerine or orange trees will show good results with HOMA experiments. It will be easy to see quickly with either of these species. Pear trees will bear sweeter fruit in HOMA atmosphere.

\section{SOIL}

Soil in HOMA atmosphere holds moisture better than any soil. It is due to the ghee and the feedback of HOMA on the atmosphere. When nutritional rain comes, the nutrients and moisture are sustained as a unit in the soil. This makes for better quality vegetation. It seems fantastic but it is true.In HOMA Therapy Organic Farming, the result of the HOMA process is that something physical interacts with the soil making the nutrients already there more potent. When nutrients are absent, cultivating the growth of nutrients necessary for healthy plant life is achieved by the HOMA process.In Agnihotra atmosphere the metabolic process of plants is sped up. It is the ghee used in Agnihotra process that is the catalytic factor and on a more subtle level the Mantras interacting with the combined effect of the burnt ghee and rice. This combination enters the soil after returning from the solar range. It enters the plants by one might say, attaching itself to minerals and water absorbed by the root system of the plant. The ghee acts like a catalyst creating a chemical reaction with the plant aiding in enzyme and vitamin production and encouraging and increasing the cyclic rate. In other words the plants mature faster, taste better and are better by mere performance of Agnihotra in the garden.Aeration of soil, of course, is an important part of gardening or farming. If HOMA ash is placed on the top of soil before it is cultivated it does a lot to help nourish the plant and make the plant happy. It is more important to make the plant happy as that is the way the plants can start to give us the feedback effect of Love.The more Love you put into the farm or garden, the more HOMA is performed, specifically revolving around Agnihotra, the greater the vibration of Love will be in the area and the happier the people will be. Also the greater and tastier the yield will be.Agnihotra and Agnihotra ash, when put on the soil, help stabilize the amount of nitrogen and potassium present.Trace elements in the soil are changing drastically. Trace elements are important to plant growth and maturation. HOMA Therapy farming is the way out. With HOMA Farming it begins to become important that all phases of nature work in harmony. Trees begin to loose their hold in the ground. The soil is having difficulty supporting life. Trees tend to fall over. HOMA and HOMA Therapy renourish the ground.The entire ecological system is benefited by HOMA. For example, earthworms are able to generate more moisture in the soil due to the performance of HOMA. HOMA makes them happy and their hormone secretion increases, thereby benefiting the soil and therefore the plants that live in the soil. The earthworm is important to farming. HOMA atmosphere increases the hormones in earthworms involved in their reproductive organs and helps multiplication of the species which in turn helps the soil to become more rich.Chemical fertilizers will prove less effective. There will be more government regulation to guard against health hazards. HOMA Therapy Organic Farming is the answer.

\section{REPRODUCTION}

Some fruits begin to increase their reproduction cycle if Agnihotra is performed in proximity to where they are grown. A plants's strength depends upon the nutrients of the soil and atmosphere that surrounds it. Science perhaps does not lay so much stress on atmosphere but it is one of the biggest factors due to the oxygen recycling system. Also if the atmosphere is filled with nutrients the plant becomes especially happy when this is done by HOMA process. This helps increase the number of seeds, the number of fertile or potentially fertile seeds germinated. Also the period of germination is helped and the quality of pollen produced is improved. The whole reproductive cycle of the plant is benefited by HOMA atmosphere.The whole ecological system is changing. The reproductive cycle of plants is changing. This effects the bees and therefore their ability to perform their role of pollination is inhibited. This adversely affects the ability of plants, especially certain vegetables, to yield and propagate.

\section{HELP FOR THE ENVIRONMENT}

The principles of life must be restated on this Earth. Everyone must be made aware that HOMA is necessary to survive. We withdraw nutrients from the environment. They must be somehow replaced. HOMA is the means.Elements begin to change. Somehow the magnetic-like pull set up where HOMA is performed, the elements required to make certain life sustaining essentials are again attracted to the planet by manifestation of some other mode of transference. Some may even come from other planets. When Agnihotra is performed there is a turbulence of electriates and ethers created by the combination of Mantras and fire that extends all the way to the solar range. This turbulence leads to a quick 


\title{
International Advanced Research Journal in Science, Engineering and Technology
}

\author{
Vol. 8, Issue 10, October 2021
}

\section{DOI: $10.17148 /$ IARJSET.2021.81026}

upheaval of the nutrient structure in the area.More people should begin to perform Agnihotra under a tree. This makes the tree happy and the tree dances and sings. Also the birds are much attracted to Agnihotra. It is healing to them.HOMA trees will soon begin to grow. They will be a species in themselves. They are now generating in intense HOMA atmosphere. Places like Amazon region of Peru is where they will be discovered.Nature is in total turmoil. So much destruction is coming now. We must saturate the atmosphere with nutrients. Ghee is the vehicle. Mantras are the power. HOMA must be done now on a large scale.

The earth has been robbed of its elements by pollution. HOMA can replace these things which are vital to all life.The Earth is wasting away. HOMA is the way to save it.

\section{INSECTS}

Inborn in the honeybees are certain hormones that are produced solely in HOMA atmosphere. This subject is foreign to anything science has encountered so far in this respect. These hormones help the nutritional levels yielded in vegetables and fruits to yield at much increased rates.

Bees are attracted to HOMA atmosphere as the amount of energy they receive from Agnihotra fire helps them to perform at a greater level of efficiency. When this is translated to pollination, they can help to increase the yields of crops. This is especially true with corn, tomatoes, berries, fruit and the like.

If a HOMA is going on round the clock in proximity to a garden, that itself is an effective aid to insect control. The atmosphere becomes saturated with ghee and the plants are able to manufacture a protective coating due to a special combination in their chemical makeup interacting with ghee absorbed by the plants by breathing. The HOMA atmosphere also creates something intangible that permits this situation to occur, which is based on the vibrational content of the atmosphere due to the Mantras going on all the time.

\section{CONCLUSION}

We take this ancient concept to the modern agiculture by implementing certain combined treatments which were working perfect. Some of those technologies are, increasing the solubility of the ash,introduction of herbal homa,introduction of Amino Acid based treatments \& alkaloids as cobo biosol improved formulations. Thus the produces received by those methods were having high bricks value \& fights against Diseases,pshcological problems such as addiction,now a days children are facingaddiction towards mobile phones

All these problems can be cleared by Homa farming

We have a detailed statergic plan which was a confidential statergy for this method

\section{REFERENCES}

1) https://www.homa1.com/agriculture/biosol.htm file:///C:/Users/Admin/Downloads/agronomy-11-00360.pdf

2) http://publicationslist.org/data/pranayabhang/ref-4/Scientific\%20study\%20of\%20Vedic\%20Knowledge\%20Agnihotra.pdf

3) https://www.aushmath.com/

4) https://backtonaturalfarm.com/index.php/2018/11/19/sunflower-microgreens-nutrition-and-health-benefits/ 